\title{
La ética: entre la mundialización y la identidad
}

\author{
Alejandro Serrano Caldera \\ Profesor visitante del programa de \\ Doctorado en Filosofía Iberoamericana, \\ Universidad Centroamericana (UCA), \\ San Salvador
}

RESUMEN: En esta conferencia dictada por el autor el 8 de septiembre de 2004, el autor discute la ética contemporánea a través del prisma de la identidad y la mundialización. Ante la fragmentación del mundo contemporáneo -y el consiguiente divorcio entre el ámbito de la ética y los de la política y la economía-, Serrano Caldera opta por un paradigma integrador, expresado en la propuesta de "unidad en la diversidad".

El tema de este trabajo toca dos aspectos de amplitud y profundidad enormes, por lo que, de entrada, debo trazar los límites del presente trabajo y poner, desde el comienzo, las cartas sobre la mesa.

Empiezo refiriéndome a las categorías de identidad y crisis, intentando darles el contenido que, desde mi punto de vista, les corresponden, en referencia específica a la realidad histórica de América Latina en sus expresiones culturales y políticas, tratando de alcanzar y criticar, desde allí, el concepto de universalidad de la modernidad.

Luego intentaré analizar el concepto de globalización, o mejor, de mundialización, de la llamada sociedad postmoderna o postindustrial, para después y siguiendo, principalmente, algunos textos de Zubiri,

La ética: entre la mundialización y la identidad 
puestos en relación con Hegel, concluir proponiendo algunas aproximaciones sobre una ética que, fundada en lo que he llamado la unidad en la diversidad, nos permita integrarnos sin degradarnos en las profundas transformaciones del mundo contemporáneo y participar con dignidad en los maravillosos avances de la ciencia y de la técnica.

Ellas, la ciencia y la técnica, aunque hacen progresar de manera extraordinaria al mundo material, no lo hacen más humano, y pueden deshumanizarlo hasta extremos intolerables, si no van acompañadas de una ética que humanice su relación con el ser humano. Es pues una forma de vislumbrar los retos de nuestro tiempo con una nueva mirada clara y limpia de prejuicios, en vez de caminar en forma mecánica y a ciegas hacia el futuro incierto de una falsa tierra prometida.

La tarea es enorme, y sería ambiciosa y desmesurada, si pretendiéramos desarrollarla en unas pocas páginas, en vez de, como intentaremos hacer, trazar las fronteras dentro de cuyo espacio plantear algunas preguntas que susciten inquietudes más que plácidas convicciones, e incertidumbres, más que tranquilizadoras certezas.

\section{Identidad, crisis y mundialización}

Los términos de identidad y crisis nos plantean dos momentos fundamentales del mundo contemporáneo. La identidad está siempre referida a la cultura, si entendemos por tal el conjunto de reflexiones $\mathrm{y}$ acciones, de creaciones y tradiciones, de formas y posibilidades, de realidades y perspectivas, de una comunidad humana determinada.

La crisis es la ruptura de los referentes habituales de una sociedad y de una época, de las ideas, pero sobre todo de las creencias y valores que constituyen la finalidad última hacia la cual la persona y la colectividad aspiran.

Convendría adentrarnos en el tema formulando algunas hipótesis de trabajo:

1. Toda cultura es síntesis.

2. Nuestra cultura es, en términos generales, una contradicción sin síntesis; una continuidad de rupturas sin restauración, una estructura de superposiciones.

3. Hay un proceso de identidad en marcha en el arte y en la literatura. 
4. No se da este proceso de identidad en el ámbito jurídico, político y social, donde más bien se presenta la bifurcación y no pocas veces la contradicción, entre el mundo real y el mundo político e institucional.

En el ámbito que corresponde al arte y al pensamiento, a la creación y a la reflexión, se ha producido un mundo propio que confiere identidad y universalidad a la cultura latinoamericana.

Si mucho se ha avanzado en el campo de las artes, la artesanía, la literatura, la filosofía, muy poco se ha conseguido, sin embargo, en cuanto a la creación de la identidad como conciencia colectiva, pues no hay que olvidar, que la poesía, la narrativa la pintura, y más aún la filosofía, se desarrollan en sectores minoritarios y privilegiados, sea desde el punto de vista cuantitativo que cualitativo

A excepción de la música popular, que ha sido en América Latina el vehículo cultural de integración más extraordinario, las otras expresiones de la cultura, como ya se ha dicho, han quedado referidas a sectores restringidos.

En cuanto a la política, ésta, por lo que influye en el comportamiento cotidiano, está llamada a ser o el más eficaz instrumento de integración o el más severo obstáculo para alcanzar la identidad. Desde la Independencia de nuestros pueblos en el siglo XIX, la política ha sido para América Latina, la expresión más visible de la crisis de identidad que la afecta.

Dos factores influyen en esta crisis. Por un lado, la estrategia preconcebida de la clase política, formada por la alianza de la oligarquía y los militares, de incorporar en las Constituciones Políticas, las ideas de la Ilustración, libertad, igualdad, y del constitucionalismo europeo, democracia, Estado de Derecho, separación de poderes, derechos y garantías individuales, para hacer deliberadamente lo contrario, de lo proclamado en la norma jurídica, manteniendo así con pocas variantes la misma estructura socioeconómica y el aparato de poder, esta vez en manos de los criollos. La estrategia y la táctica fueron decir lo que no se hace, para hacer lo que no se dice.

La democracia retórica que de ahí procede se hace evidente en la incongruencia entre sus enunciados constitucionales y la realidad política, económica y social. 
Por otro lado, la visión de la bistoria de la generación que impulsa la "segunda independencia" de las Repúblicas americanas se resume en el inocente optimismo de Sarmiento en Civilización y Barbarie, versión criolla del diálogo entre Próspero y Calibán de Shakespeare, que Leopoldo Zea analiza magistralmente en su obra. El pasado americano y precolombino es la barbarie; la industria europea es la civilización y el futuro de América.

Renunciamos así a lo que hemos sido y somos por lo que nunca seremos. Hipotecamos nuestra realidad por un futuro que no acaba de llegar porque no es el nuestro y porque no hay futuros prestados.

Los latinoamericanos, desde la independencia hasta hoy no hemos aprendido bien la lección, y, por supuesto, hemos pagado y continuamos pagando muy caro nuestra superficialidad en el tratamiento de la política y la historia. La identidad política es una condición de la identidad, a secas. Alcanzarla es un desafío ineludible que nos presenta la historia y la cultura.

La identidad, por otra parte, es condición de la universalidad. Identidad y universalidad son términos indisociables. Sólo se tiene identidad en la medida en que las expresiones particulares se integran a la universalidad de las culturas. Sólo se alcanza la universalidad, cuando esta se forma por la convergencia de múltiples determinaciones, por lo que hemos llamado la unidad en la diversidad.

Como nos recuerda Carlos Fuentes, "el pacto de civilización consiste en reconocer que somos un área policultural, dueña de una enorme variedad de tradiciones de donde escoger elementos para un nuevo modelo de desarrollo y sin razones para estar casado con una sola solución. Nuestra cartelera no se limita a escoger entre los Chicago Boys y los Marx Brothers. Somos parte de las Américas que tiene viva una tradición indígena y una tradición medieval, agustiniana y tomista. La América española sí tuvo una civilización preeuropea y una cultura política medieval. El valor de la historia es su variedad concreta y no su uniformidad abstracta". ${ }^{1}$

Junto a esta crisis no resuelta que hemos intentado describir en los párrafos anteriores, se agrega una nueva que se desprende del cuadro general de la estructura económica, sociológica, política y cultural del mundo, de eso que en forma imprecisa y contradictoria han llamado 
postmodernidad y que yo preferiría denominar transmodernidad. "Llamarse postmoderno, como dice Octavio Paz, es seguir siendo prisioneros del tiempo lineal progresivo", que caracteriza a la modernidad.

No obstante, el término postmodernidad ha tomado carta de ciudadanía y pese a la reserva que he dejado asentada, me veré obligado a utilizarlo por ser de uso común.

En mi libro El doble rostro de la postmodernidad ${ }^{2}$, intento, desde el título, identificar la ambigüedad y, más que eso, la contradicción, entre la filosofía y la práctica del fenómeno postmoderno. Por una parte, se presenta lo que sus filósofos han llamado la desconstrucción de los modelos y los arquetipos que propone un paradigma de sociedad universal, y por la otra, en el terreno de las realidades, se construye una sociedad homogénea y estandarizada mediante los procesos de globalización.

Al sentido unitario de los objetos en la modernidad, se agrega ahora el sentido transitorio de los mismos en la postmodernidad. Lo utilitario y lo transitorio de las cosas se han impuesto en la sociedad de consumo, y en la sociedad consumida, como valor absoluto al cual deben subordinarse todos los otros. Nunca como ahora se han descartado las cosas con tanta rapidez a causa de lo preciso de su duración.

Mientras más rápidamente se descartan unos objetos, más rápidamente se sustituyen por otros y más se consumen. Mientras menor es la vida de los objetos y más rápida su sustitución por las nuevas cosas, mayor es la dependencia que generan. Las cosas duran poco para que el hábito que produce dure mucho.

La lógica del consumo es la misma de la droga. Mientras más y más rápidamente se destruye el objeto al consumirlo mayor es la dependencia al mismo y más irresistible el hábito de consumo. Mientras por un lado todo se fragmenta y pulveriza (valores, sujetos, modelos), se mundializa un nuevo absoluto, el habito del consumo, el que contrasta brutalmente en las sociedades que no producen y en donde masas enormes de indigentes no tienen que consumir, ni siquiera los productos necesarios para la sobrevivencia.

Por ello, sociedades como las nuestras viven insertas en una pseudo realidad en la que se imponen las pautas de la sociedad de consumo, 
sin haber llegado a la economía de consumo. Jamás como ahora el ser humano ha sido tan dependiente de los objetos de su creación, pues, como dijo Marx, los objetos no son ya producidos para satisfacer las necesidades, sino las necesidades producidas para satisfacer los objetos.

¿Recuerdan a Frankenstein? ¿Aquel monstruo con pretensiones de humano surgido de las brumas de Transilvania y de las del cerebro del sabio que la inventó?. ¿Aquel ser desmesurado, a la vez brutal y tierno, que termina revelándose y rebelándoles a su creador?. Creo que es la imagen más precisa para expresar la sociedad contemporánea. Patética metáfora del drama de nuestro tiempo en el que los objetos, o sus símbolos, se han impuesto sobre las personas, en donde las criaturas esclavizan a los creadores, en donde se fragmenta todo y se descartan objetos y personas.

Por eso es absolutamente imprescindible humanizar el progreso y construir una verdadera ética del desarrollo, volver a las fuentes originales de la razón que fue sinónimo de libertad y del humanismo que lo fue del respeto a la vida y a la dignidad integral de la persona. Por ello debemos volver a la cultura que debe ser vida y pasión, palpitante siempre aun en aquellos casos en que aparenta ser despojo yerto de un pasado por siempre ido.

Debemos preservar nuestras esencias culturales para trascenderlas en un horizonte universal en el que amanece un futuro promisorio. Esto exige hacer del pasado una realidad viva, pues la única forma de evitar que el presente sea pasado es haciendo que el pasado palpite en el presente.

Es imprescindible un proceso de humanización de la ciencia, la técnica y las propias humanidades, para rescatar las diferencias culturales como testimonio de una humanidad plural y un mundo verdaderamente humano.

El problema de la identidad ha sido quizás el problema esencial de nuestra cultura. Ha estado presente ante el fenómeno de la modernidad y lo está ante la postmodernidad. La Modernidad se caracteriza, principalmente, por la crítica, la racionalidad y la utopía. "La Edad Moderna, dice Octavio Paz, se inicia con la crítica a la eternidad cristiana y con la aparición de otro tiempo". "La Modernidad desvaloriza a la eternidad; la perfección se traslada al futuro, no en el otro mundo 
sino en este". "La siempre diferida perfección residió en el futuro. Los cambios y sus revoluciones fueron encarnaciones del movimiento de los hombres hacia el futuro y sus paraísos"” ... "La Modernidad nació con la afirmación del futuro como tierra prometida". ${ }^{4}$

Si la crítica es rasgo distintivo de la Modernidad también lo es la Utopía, que es la enunciación de la tierra prometida, del reino del futuro. No obstante, la utopía de los filósofos de la modernidad no es una propuesta irracional, sino, al contrario de lo que habitualmente se cree, pretende ser la máxima expresión de la racionalidad, el sumo esfuerzo de la razón por construir una sociedad perfecta y teóricamente pura como puede ser una figura geométrica, como el triángulo, por ejemplo, situado como concepto más allá del tiempo y del espacio y, por lo tanto, eterno e inmutable.

A diferencia del mito que es una experiencia arracional, la utopía es una formulación esencial al racionalismo. Podríamos decir que el mito es la utopía arracional, y que la utopía es el mito que inventa la razón. La exacerbación de los modelos racionales y el empeño vano de querer reducir la realidad a fórmulas abstractas ha llevado, en virtud de una extraña dialéctica, a la paradoja de transformar en irracionales las propias propuestas de la razón conducidas al extremo.

En lo que concierne al problema de la identidad, en América Latina, habría que decir que estamos enfrentados a un desafío que exige de todos lucidez y decisión, para evitar que una falsa universalidad confundida con la globalización disuelva en una estandarización planetaria los rasgos esenciales de las diferencias culturales, y, correlativamente, para contribuir a la formación de una verdadera universalidad que se construya sobre la base del diálogo de las culturas.

Creo que éste es un problema ético fundamental de nuestro tiempo que constituye un desafío que los intelectuales no debemos eludir. $\mathrm{Ni}$ la cultura de aldea que reduzca nuestras posibilidades a un falso folklore, ni la uniformidad que anula los rasgos esenciales de las culturas y las especificidades de las diferencias.

Un nicaragüense, Rubén Darío, nos ha dado desde hace tiempo una lección que no debemos olvidar. En sus dilucidaciones que preceden al Canto errante, dice: "La actividad humana no se ejercita por medio de la ciencia y de los conocimientos actuales, sino en el vencimiento del tiempo y del espacio. Yo he dicho: es el arte el que vence

La ética: entre la mundialización y la identidad 
al espacio y al tiempo. He meditado ante el problema de la existencia y he procurado ir hacia la más alta idealidad. He expresado lo expresable de mi alma y he querido penetrar en el alma de los demás $y$ hundirme en la vasta alma universal". ${ }^{5}$

Sus ansias de universalidad en el arte, con las que se opone a todo provincianismo, no apagan su fe en las tradiciones. "He comprendido, dice, la fuerza de las tradiciones en el pasado y de las previsiones en lo futuro". ${ }^{6}$ Su poesía tiende a trascender la historia, "que está hecha de épocas fugaces construida sobre momentos soberbios como Palenque y la Atlántida con que puntúa Dios los versos de su augusto poema". ${ }^{7}$

La reafirmación de la identidad hispanoamericana se encuentra sobre todo en "Salutación del optimista", manifiesto de la raza y de nuestra civilización, con que golpea y sacude para despertar conciencias adormecidas, pues somos frutos de "... dos continentes abonados de huesos gloriosos". ${ }^{8} \mathrm{Y}$ así clama: "Únanse, brillen, secúndense, tantos vigores dispersos; formen todos un sólo haz de energía ecuménica/ Sangre de Hispania fecunda, sólidas ínclitas razas/ muestren los dones pretéritos que fueron antaño su triunfo".?

Y así reclama la síntesis que es la que finalmente hace posible toda civilización y toda cultura y apela a las savias dormidas (múltiples) para que despierten en el tronco del roble gigante bajo el cual se exprimió la ubre de la loba romana (unidad originaria).

Todo se une en la invocación del espíritu de la raza: leche, miel, savia y sangre; la loba romana, los manes antiguos, primitivos abuelos, viejas prosapias. dioses y hombres unidos en un pretérito anterior a la historia y al tiempo.

Formidable ejemplo hoy más vigente que nunca que nos enseña que en la adecuada relación entre la identidad y los valores generales de todas las culturas, se encuentra la verdadera universalidad y la ética que la sustenta.

\section{La ética y la praxis: Una reflexión sobre Zubiri y Hegel}

La obra de Zubiri tiene un núcleo importante en sus reflexiones sobre inteligencia y sensibilidad, principalmente en sus obras Inteligencia sentiente e Inteligencia y Logos. 
Nos interesa particularmente su pensamiento por la integración y la síntesis que hace entre inteligencia y sensibilidad, lo que nos conduce a colegir la integración y la síntesis entre razón, y realidad y asumir como condición inevitable de toda ética, la relación entre el hombre y su mundo, entre el yo y la circunstancia como diría Ortega y Gasset

Para construir la reflexión que nos ocupa, hemos tratado de seguir la argumentación de Zubiri contenida en su obra Inteligencia sentiente. En esa línea de pensamiento, empezaríamos diciendo que para Zubiri es "imposible una prioridad intrínseca del saber sobre la realidad ni de la realidad sobre el saber. El saber y la realidad son en su misma raíz estricta y rigurosamente congéneres". ${ }^{10}$

Esto implica que el estudio del saber no es anterior al estudio de la realidad. ¿Podríamos legítimamente percibir en este enunciado zubiriano ecos ocultos de Hegel que, pareciera inevitable, todo filósofo moderno lleva dentro? ¿Sería válido pensar que tras la formulación de Zubiri se encuentre aquella otra de Hegel, todo lo real es racional; todo lo racional es real?. Pienso que no. En Hegel lo real proviene de lo racional, de la razón total que es el espíritu. Todo lo demás es enajenación de ese espíritu a través de las diferentes etapas de su desenvolvimiento: Espíritu subjetivo, Espíritu objetivo, Espíritu absoluto.

En Zubiri, en cambio, hay una deliberada repulsa de toda crítica del saber como fundamento previo de lo real. "Porque la filosofía moderna no comienza con el saber sin más, sino con ese modo de saber que se llama conocimiento. La crítica es así crítica del conocimiento, de la episteme, o como suele decirse, es epistemología, ciencia del conocimiento. Y lo reafirma categóricamente: "Porque el conocimiento no reposa sobre si mismo"... "Porque lo primero del conocimiento está en ser un modo de intelección"."11

"La espistemología — dice- presupone una investigación de lo que estructural y formalmente sea la inteligencia, el nous, el estudio de noología". ${ }^{12}$ Zubiri se alza contra la concepción tradicional de toda la filosofía occidental desde Parménides, la que separa dos acciones intrínsecamente enlazadas, consubstanciales, si acaso es procedente el uso del término al hablar de la filosofía de Zubiri. 
"Una cosa se nos dice es sentir, otra inteligir. Este enfoque del problema de la inteligencia contiene en el fondo una afirmación: inteligir es posterior a sentir, y esta posterioridad es una oposición. Fue la tesis inicial de la filosofía desde Parménides, que ha venido gravitando imperturbablemente, con mil variantes, sobre toda la filosofía europea”. ${ }^{13}$

Pero indubitablemente esta afirmación contiene otra como su consecuencia. En efecto si el sentir es anterior al inteligir, la sensación o acto sentiente tiene un carácter no sólo a-lógico sino también prelógico, de donde resulta que sentir es un acto primario común a toda naturaleza animal, incluyendo al animal humano, en tanto que inteligir es un estadio superior que corresponde exclusivamente al ser humano. Esta afirmación nos lleva inevitablemente a otra: la intelección no es otra cosa que el ordenamiento racional de los datos sensibles que el hombre percibe por los sentidos.

Contra esta separación se alza la filosofía de Zubiri. "Se nos dice a lo sumo que los sentidos dan a la inteligencia las cosas reales sentidas para que la inteligencia las conceptúe y juzgue de ellas. (...) "Resulta que esta apelación de las cosas reales en cuanto sentidas es una aproximación sentiente; pero en cuanto es una aprehensión de realidades, es aprehensión intelectiva. De ahí que el sentir humano y la intelección no sean dos actos numéricamente distintos, cada uno completo en su orden, sino que constituyen dos momentos de un sólo acto de aprehensión sentiente de lo real: es la inteligencia sentiente". ${ }^{14}$

Zubiri deja bien claro que lo inteligente y lo sensible no se determinan en tanto que la una actúa sobre la otra y viceversa, sino que ambas forman parte de una unidad que las contiene. "No se trata de inteligir lo sensible y sentir lo inteligible, sino que inteligir y sentir constituyen estructuralmente (...) una sola facultad, la inteligencia sentiente" (...) "Inteligir es un modo de sentir y sentir en el hombre es un modo de inteligir". ${ }^{15}$

La filosofía de Zubiri se separa así de manera bien clara de la filosofía griega y medieval que consideraban el inteligir y el sentir "como actos de dos facultades esencialmente distintas". Intelección es aquí aprehensión y aprehensión es aprehensión de lo real que integra ya en su totalidad los dos momentos referidos: el de la sensibilidad y el de 
la intelección. El acto de aprehensión implica la apropiación de lo otro entendido, precisamente en su propia alteridad.

"Alteridad no es solamente el carácter abstracto de ser alter. Porque alteridad no consiste en que la afección nos haga presente algo meramente otro; por ejemplo, este sonido o este color verde. Sino que nos hace presente esto otro en una precisa forma; lo otro pero en tanto que otro". ${ }^{16}$

La inteligencia sentiente de Zubiri es una categoría fundamental de la filosofía que permite transponer los limites que han atrapado a ésta dentro del ámbito de un filosofar anclado en pensar sólo el pensamiento, desertando de la tierra "en nombre de los trasmundos".

Zubiri se sitúa en un horizonte auténticamente contemporáneo. Integra lo racional y lo real en forma constitutivamente dialéctica y no causal, como en Hegel, en donde la razón es la causa absoluta de toda realidad. Por otra parte, la gigantesca síntesis hegeliana quedó presa del "horizonte moderno de la subjetividad".

La inteligencia sentiente nos conduce no solamente a un concepto integrativo de ambas categorías que devienen funciones de una misma unidad, sino que necesariamente nos conduce a reconocer en esta relación entre lo inteligente y lo sentiente una ética y una praxis. Una ética fundada en una praxis. La ética debe consistir en la praxis de una actividad creativa que ponga con relación al hombre y su mundo, no sólo circundante, sino, a la vez constituyente y constituido y que lo libere de la alienación y la deshumanización. El hombre no sólo es producto de la naturaleza sino factor que la determina y transforma.

El horizonte hegeliano es el de la razón total que constituye, comprende y determina. "El horizonte post hegeliano es el horizonte de la praxis". ${ }^{17}$

Los análisis de Heidegger y los de casi toda la filosofía occidental desde Parménides, con excepción, quizás, de la izquierda hegeliana, han considerado la sensibilidad humana como algo ajeno a la intelección. De ahí se desprende que de la sensibilidad sólo se derivan procesos de adaptación pero no de transformación, pues estos últimos son frutos de la inteligencia y más concretamente de la acción de la razón en al historia. 
Ante los acontecimientos del mundo contemporáneo podríamos decir, utilizando las categorías de Zubiri, que la globalización o la mundialización, tienen como presupuestos la deshumanización del hombre por causa de su sometimiento a una fórmula universal uniformadora.

Zubiri extiende el horizonte de la praxis a lo sentiente y no lo limita, como Marx, estrictamente a la actividad laboral. La función radical de la racionalidad del ser humano es la búsqueda y apropiación de posibilidades, lo que exige, inevitablemente, partir de la inextricable integración entre el hombre y el mundo. Este enfoque aproxima a Zubiri al Marx de la Tesis sobre Feuerbach, cuando expresa que las circunstancias cambian por la acción del hombre y que el educador necesita también ser educado.

\section{En la búsqueda de una nueva ética}

La presencia humana en el mundo no es únicamente una consecuencia de la naturaleza, sino una praxis que la determina y transforma. El ser humano transforma y al transformarlo crea el mundo en que vive y se transforma y re-crea a si mismo. A partir de esta consideración, el concepto de lo humano deriva no ya de una esencia determinante y constitutiva, sino de la interacción entre el hombre y el mundo.

"De este modo -dice Antonio González-, la actividad humana no es sólo una determinación antropológica, sino que tiene un carácter rigurosamente metafísico; la mutua imbricación entre le hombre y el mundo es el horizonte mismo de toda pregunta por la realidad".(...) "El individualismo no haría sino reflejar en filosofía la imagen deformada que el hombre se hace de si en un sistema socioeconómico, en definitiva, fundado sobre lo que Marx denominaría la escisión entre su ser individual y su ser genérico. (...) La praxis humana es constitutivamente social porque toda actividad del hombre esta socialmente articulada". ${ }^{18}$

La actividad sentiente se produce no en una relación pasiva en virtud de la cual el hombre recibe poco menos que estático los mensajes de la naturaleza y el mundo exterior, sino mediante un proceso intelectivo que implica la acción intelectiva y la praxis humana. La praxis se amplía hacia un horizonte integral de la experiencia humana 
en relación con el mundo, lo que a su vez conlleva a una actitud ética mediante la cual el ser humano atribuye a su acción un determinado valor.

"La pregunta ética —dice Antonio González- se nos muestra como una pregunta insoslayablemente política. El saber ético ha de consistir por lo tanto en una interrogación por la actividad del hombre en cuanto que, genéricamente, no se limita a ser producto de un medio natural del carácter que sea, sino que, además, y sobre todo, específicamente modeladora del mundo en que ha aparecido. Pero además, esta pregunta solamente se puede plantear de un modo auténtico y pleno si entre las realidades que el hombre socialmente transforma a lo largo de su historia, se incluyen también las realidades sociales, morales y políticas que el mismo ha creado". ${ }^{19}$

La filosofía de Zubiri, junto a la de otros filósofos contemporáneos, o en las fronteras de la contemporaneidad, Nietzsche, Heidegger, Levinas, guardando las distancias de sus propias identidades y diferencias, trasciende las fronteras de la modernidad y se sitúa en un horizonte post-hegeliano. El sistema de Hegel lo integró todo - del guijarro a la estrella- y lo totalizó todo. Nada existe por fuera de la realidad absoluta del espíritu ni del totalitarismo de la razón.

La filosofía de Hegel elevó la dialéctica a su más alta expresión y le dio una fundamentación teórica a las profundas transformaciones de la historia. Todo ello, no obstante, bajo el imperio de la razón en cuyos dominios no se pone el sol. La revolución para Hegel no era otra cosa que la inserción de la razón en la historia. Sobre esta racionalidad la propia historia ha sido su mayor crítica.

Marx transformó la metafísica de la razón de Hegel en una filosofía de la historia construida a partir de las propias realidades materiales y actuando conforme pretendidas leyes científicas. La historia ha dado también respuestas contundentes a este afán de querer aprisionar el azar en la necesidad y congelar ese acontecer de imprescindible novedad del que hablaba Bergson.

La enajenación que Marx desarrolló lucidamente en los Manuscritos económicos y filosóficos, tuvo su antecedente en la categoría de Positividad del joven Hegel de los años del Seminario de Tubinga. No obstante la enajenación de Hegel no tomó en consideración "la

La ética: entre la mundialización y la identidad 
realidad real", hipostasiando aquella en la esencia universal del Espíritu fuente absoluta de toda experiencia natural y humana. La filosofía de Hegel terminó siendo en el pensamiento de Occidente un subjetivismo racional absoluto; el paradigma y el arquetipo de la razón, en cuyo nombre se cometen las más crudas irracionalidades y bajo cuyas banderas trata de justificarse todo: la mundialización, la supresión de las diferencias, la muerte de las identidades, el eclipse de la cultura, la idolatría del mercado, y tantas otras profecías de tecnócratas iluminados.

Al inicio de este siglo, el mundo que creó Hegel parece derrumbarse, su sistema no oculta ya sus resquebrajaduras y el horizonte de su pensamiento que parecía ilimitado, deja entrever a lo lejos las fronteras que lo circundan y aprisionan. Curiosamente cuando esto ocurre los guardianes del universo tecnológico y de la sociedad postindustrial que hasta no hace mucho lo tenían proscrito, lo adoptan ahora como el padre del pensamiento que trasciende los muros del siglo XX y se proyecta más allá del horizonte del siglo XXI.

No obstante, la ética que deriva de su sistema y que hoy invocan sus acólitos de nuevo cuño, es no sólo insuficiente, sino negativa para enfrentar los desafíos que impone el cambio de mundo que nos amenaza y deforma, que gozamos y padecemos.

Una nueva ética exige esa integración inextricable entre praxis y eticidad determinadas todas por el reconocimiento de la indisoluble relación entre el hombre y el mundo, de la socialidad del ser humano y de la consecuencia que ella conlleva en tanto que compromiso con la naturaleza, con la sociedad, con el hombre.

Una nueva ética que trascienda la ética del discurso que nos proponen Karl-Otto Apel y Jürgen Habermas, de la Escuela de Francfort y que implique, por lo mismo, solidaridad que deriva de la acción y de la experiencia humanas, respeto a la diferencia, pluralidad y diálogo de las culturas, reconocimiento del otro, en tanto que actuación del principio de alteridad, en fin, realización de eso que yo me he permitido llamar aplicándolo a la ética, la historia y la política: Unidad en la diversidad.

Un nuevo pensamiento y una nueva conducta que nos lleven a la legitimación de las diferencias y a la recuperación de la identidad. A 
fundamentar la moral del nuevo tiempo en el reconocimiento de la heteronomía de la que nos habla Levinas en Totalidad e infinito y en su crítica a la filosofía occidental, el que, como dice Antonio Sidêkum, tiene su propia repercusión como principio transparadigmático en la filosofía y en la teología de la liberación, lo mismo que en la búsqueda de una fundamentación para un nuevo orden social.

En síntesis, se trata de reivindicar por la ética y para la historia y la política, el derecho de todos a su propia praxis, enfrentados cada quién a su propio mundo, con sus virtudes y defectos, grandezas y brutalidades, convergencias y diferencias. Se trata de reivindicar el derecho a la identidad y a la diferencia; y la acción legítima de negar como válido un concepto de universalidad que se funda en la homogeneidad y en la estandarización, reivindicando, en cambio, un concepto de universalidad enriquecido por la pluralidad de expresiones culturales que se han forjado a lo largo del tiempo a partir de su propia ética y de su propia praxis. Sólo así será posible dignificar la presencia del hombre en la historia y de prolongar su fecunda labor creativa.

La perversión de valores que se introyectan en el Sur pobre y empobrecido, comienzan con el establecimiento de paradigmas que no corresponden a su propia realidad.

Por ello la obligación de filósofos e intelectuales (hubiera querido incluir también a los políticos) exige que se combatan las pretensiones de querer institucionalizar la enajenación fundamento de casi todos los males morales y materiales padecidos.

La filosofía latinoamericana de la liberación, uno de cuyos principales exponentes es Enrique Dussel, ha combatido la pretensión filosófica occidental de considerar su propia realidad teórica y práctica como la única realidad universal, reivindicando la Filosofía de la Liberación, la legitimidad de la alteridad y reclamando la liberación del oprimido y la inserción en la historia del "otro", del excluido, de aquel a quien se le niega su condición de humanidad y su realidad de sujeto. La influencia de Emmanuel Levinas es determinante en la formulación de la Filosofía y la Teología de la Liberación cuyo aporte disidente constituye un patrimonio indiscutible del pensamiento universal contemporáneo. 


\section{La Unidad en la diversidad como propuesta ética}

No obstante, el reto, a mi juicio, es más grande, difícil y complejo, pues aun suponiendo que lo "otro", o el "otro", lleguen a ser reconocidos, lo que histórica y políticamente implica que el "excluido" se libera de su exclusión y opresión mediante su lucha, las categorías mentales y morales y el aparato concreto de la dominación quedan intactos pudiendo reeditar nuevas y variadas formas de dominación o continuar con la misma sobre otros sujetos.

Por ello, a mi juicio, la nueva filosofía y la nueva ética, deben considerar un doble plano teórico y práctico de acción: el referido a la situación histórica del "tercero excluido", es decir, del "otro" que concretamente busca superar su exclusión y enajenación insertándose como sujeto en la historia, esto es, liberándose; y el referido a la filosofía y ética dominantes de Occidente, que solo confieren valor de universalidad a lo propio y solo reconocen lo que es idéntico al modelo dominante, sin otros rostros que el propio reflejándose en múltiples espejos.

La situación analizada exige que el reconocimiento de lo "otro" no sea solamente el reconocimiento de lo otro como exterioridad, sino el reconocimiento de lo otro como formando parte de una nueva interioridad complementaria, esto es, como parte constitutiva de una unidad diferente de la unidad de lo "uno hasta abora dominante". Tratando de decirlo en otra forma, esto significa que cada factor (lo "uno" y lo "otro", llamémosle así por el momento) se constituye complementariamente mediante un sistema de influencias recíprocas, de una interacción de "la unidad en la diversidad".

Precisando los alcances de esta nueva ética es oportuno puntualizar lo siguiente: se impone reconocer que la existencia del otro existe independientemente del reconocimiento que de él haga el uno; que debe existir una relación de reconocimiento recíproco entre el uno y el otro.

Este reconocimiento no debe entenderse como:

- Un reconocimiento externo al otro (el excluido) por parte del uno;

- Ni siquiera como una integración del otro en el universo del uno, sino; 
- Como una relación interdependiente y una integración intercurrente, bilateral, biunívoca. Complementaria y dialéctica, formando como consecuencia de esa relación un nuevo mundo en el que, no obstante, el uno y el otro conservan su identidad.

Creo que en el posterior desarrollo de estas categorías, el concepto de "alteridad", y de otros aquí trabajados, va a continuar siendo un aporte imprescindible en los esfuerzos de construir una nueva filosofía, una nueva ética y un nuevo humanismo.

Después de todo lo dicho podríamos afirmar categóricamente que estamos situados en el horizonte post-hegeliano? ¿Después de este alejamiento crítico de Hegel no queda, sin embargo, un sabor a la Fenomenología del Espíritu y a La dialéctica del amo y del esclavo, según la cual la liberación total solo adviene cuando se hayan liberado finalmente los oprimidos y los opresores?

Pero éste puede ser el tema de otra reflexión. Mientras tanto, es prudente concluir aquí... por el momento.

\section{BiBLIOGRAFÍA}

Bergson, Henri. Memoire et vie. Presses Universitaires de France. Vendome.

Dussel. Ética de la Liberación. En la edad de la globalización y la exclusión. Editorial Trotta. Madrid.

Fuentes, Carlos. Valiente Mundo Nuevo. Fondo de Cultura Económica. México.

González, Antonio. El hombre en el Horizonte de la Praxis. Estudios Centroamericanos. ECA. San Salvador.

Hegel, Federico. Fenomenología del Espíritu. Fondo de Cultura Económica. México DF. México

Lecciones sobre la Filosofía de la Historia Universal. Ediciones de la Revista de Occidente. Madrid.

Levinas, Emmanuel. Totalidad e Infinito. Ediciones Sígueme. Salamanca.

Marx, Carlos. Manuscritos Economía y Filosofía. Alianza Editorial. Madrid. 
Paz, Octavio. La Otra Voz. Seix Barral. Barcelona.

Rubén Darío. Poesía. Editorial Nueva Nicaragua. Managua, Nicaragua

Serrano Caldera, Alejandro. El doble rostro de la postmodernidad. CSUCA Editorial El Amanecer. Managua.

- La Unidad en la Diversidad. Ediciones Progreso. Managua.

Zea, Leopoldo. Filosofía de la Historia Americana. Fondo de Cultura Económica. México.

Zubiri, Xavier. Inteligencia Sentiente. Alianza Editorial. Madrid.

\section{Notas}

1. Carlos Fuentes. Valiente Mundo Nuevo. Fondo de Cultura Económica. México, DF. México

2. Alejandro Serrano Caldera. El Doble Rostro de la Postmodernidad. CSUCA. Editorial El Amanecer. Managua, Nicaragua

3. Octavio Paz. La Otra Voz. Seix Barral. Barcelona, España

4. Octavio Paz. Ob.Cit.

5. Rubén Darío. Poesía. Editorial Nueva Nicaragua. Managua, Nicaragua

6. Rubén Darío. Ob. cit.

7. Rubén Darío. Ob. cit.

8. Rubén Darío. Ob. cit.

9. Rubén Darío. Ob. cit.

10. Xavier Zubiri. Inteligencia Sentiente. Alianza Editorial. Madrid, España

11. Xavier Zubiri. Ob. cit.

12. Xavier Zubiri. Ob. cit.

13. Xavier Zubiri. Ob. cit.

14. Xavier Zubiri. Ob. cit.

15. Xavier Zubiri. Ob. cit.

16. Xavier Zubiri. Ob. cit.

17. Antonio González. El Hombre en el Horizonte de la Praxis. Estudios Centroamericanos. ECA. San Salvador, El Salvador

18. Antonio González. Ob. cit.

19. Antonio González. Ob.cit. 